\title{
Dexamethasone Increases Hippocampal Neuronal Apoptosis in a Rabbit Model of Escherichia coli Meningitis
}

\author{
ANNETTE SPREER, JOACHIM GERBER, MAREIKE HANSSEN, STEFANIE SCHINDLER, CORINNA HERMANN, \\ PETER LANGE, HELMUT EIFFERT, AND ROLAND NAU
}

\author{
Department of Neurology [A.S., J.G., M.H., P.L., R.N.], Department of Medical Microbiology [H.E.], University Hospital, \\ Georg-August-University of Göttingen, 37075 Göttingen, Germany; Department of Biochemical Pharmacology [S.S., C.H.], University of \\ Konstanz, 78457 Konstanz, Germany
}

\begin{abstract}
Mortality and long-term sequelae rates are high among adults and children with acute bacterial meningitis. Adjunctive treatment with dexamethasone has been shown to reduce systemic complications in bacterial meningitis patients, but corticosteroid treatment may have detrimental effects on hippocampal function. We evaluated the effect of dexamethasone treatment in addition to antibiotic therapy in a rabbit model of Escherichia coli meningitis. A moderate anti-inflammatory effect of dexamethasone could be demonstrated with respect to the inflammatory mediator prostaglandin E2, whereas no significant effect of dexamethasone on tumor necrosis factor- $\alpha$, cerebrospinal fluid pleocytosis, protein, lactate, indicators of global neuronal damage, or blood gas analysis was found. Dexamethasone, however, increased the rate of apoptotic neurons in the granular layer of the hippocampal dentate gyrus. In view of the proapoptotic effect of adjunctive dexamethasone on hippocampal neuronal cells in animal models of Gram-positive and Gram-negative meningitis, the application of dexamethasone should be considered carefully in those forms of bacterial meningitis for which no evidence-based data of beneficial effect in humans are available, such as neonatal meningitis, bacillary Gram-negative meningitis or nosocomial forms of meningitis (e.g. following neurosurgery). (Pediatr Res 60: 210-215, 2006)
\end{abstract}

$\mathrm{B}$ acterial meningitis continues to be associated with high mortality and neurologic sequelae rates worldwide. Neurologic sequelae include epileptic seizures, mental retardation, and learning disorders. The impairment of the CNS is caused by stimulation of the host's systemic and local immune defense (invasion of leukocytes, activation of resident immune cells such as microglia, dysfunction of the blood-brain barrier, release of cytokines) and by direct toxicity of bacterial products (1). Standard therapy for bacterial meningitis is based on high doses of bactericidal cell wall-acting antibiotics such as $\beta$-lactams or vancomycin, which act by bacteriolysis. Despite rapid sterilization of the CSF, worsening of clinical symptoms after initiation of antibiotic treatment during meningitis has been frequently observed, most probably as a consequence of a burst of inflammation caused by the liberation of proinflammatory bacterial compounds (2). In accord with these clinical

Received November 15, 2005; accepted March 21, 2006.

Correspondence: Roland Nau, M.D., Department of Neurology, University Hospital, Georg-August-University of Göttingen, Robert-Koch-Str. 40, 37075 Göttingen, Germany; e-mail: rnau@gwdg.de

This work was supported by the Deutsche Forschungsgesellschaft (grant Na 165/4-3). DOI: $10.1203 / 01$.pdr.0000227553.47378.9f observations, a mouse model of pneumococcal meningitis showed an immediate massive increase of glial fibrillary acidic protein as an indicator of parenchymal glial activation after onset of bacterial killing by ceftriaxone (3). Elevated levels of inflammatory mediators such as cytokines and prostaglandins are common in the CSF of infants and children with bacterial meningitis and useful in evaluating the intensity of the inflammatory process in the CNS $(4,5)$.

Adjunctive treatment with dexamethasone is an important anti-inflammatory approach investigated with conflicting results during the last decades. Several important studies have been published recently. In 2002, the European Dexamethasone in Adulthood Bacterial Meningitis Study showed a beneficial effect of adjunctive dexamethasone treatment on clinical outcome at $8 \mathrm{wk}$ in patients with pneumococcal meningitis (6). A post hoc analysis of this study revealed that the beneficial effect of dexamethasone on mortality rate was attributable to a reduction of systemic complications, comparable to low-dose corticosteroid treatment in patients with septic shock (7). In the meningitis study, however, no reduction of the frequency of neurologic sequelae after the observation period of $8 \mathrm{wk}$ could be demonstrated (8). The beneficial effect of adjunctive dexamethasone treatment observed in European countries was absent under the conditions of developing countries $(9,10)$.

In contrast to the anti-inflammatory and putatively beneficial effect of glucocorticoids, dexamethasone aggravates the apoptotic neuronal damage in the hippocampal dentate gyrus in animal models of pneumococcal meningitis $(11,12)$, resulting in greater learning and memory impairment (12). Neuronal apoptosis also occurs in the hippocampal formation of patients during bacterial meningitis (13), and bilateral hippocampal atrophy seen by magnetic resonance imaging in patients who survived meningitis is considered one cause of the frequent long-term neuropsychological and cognitive sequelae (14). Presently, under conditions in developed countries, adjunctive dexamethasone is unequivocally beneficial in children with

Abbreviations: CFU, colony-forming units; CSF, cerebrospinal fluid; HE, hematoxylin-eosin (staining); NSE, neuron-specific enolase; PGE2, prostaglandin E2 
Haemophilus influenzae meningitis $(15,16)$ and in adults with pneumococcal meningitis (8). Routine use of dexamethasone is currently not recommended for the treatment of meningitis caused by less common pathogens, such as in neonatal meningitis, bacillary Gram-negative meningitis, and nosocomial meningitis $(17,18)$.

The present study addresses whether the detrimental effect of dexamethasone on the hippocampal dentate gyrus is a feature of experimental pneumococcal meningitis only, or whether it also occurs with other pathogens. Escherichia coli $\mathrm{K} 1$ is the most common Gram-negative organism causing neonatal meningitis with high mortality and long-term sequelae $(19,20)$. In adults, spontaneous meningitis due to non- $H$. influenzae-Gram-negative bacilli (mostly E. coli) usually occurs in immunocompromised patients or following accidental or neurosurgical trauma of the head or the spine, but is also observed as community-acquired meningitis in the elderly $(21,22)$. Here we evaluated the effect of adjunctive dexamethasone treatment in a rabbit model of Gram-negative E. coli-meningitis on the inflammatory response within the $\mathrm{CSF}$ and neuronal damage.

\section{METHODS}

Pathogen. An E. coli K1-strain isolated from a child with neonatal meningitis (gift of Dr. G. Zysk, Institute of Medical Microbiology, Düsseldorf, Germany) was cultured on blood agar plates at $37^{\circ} \mathrm{C}$, harvested with $0.9 \%$ saline and preserved in aliquots containing $10^{10} \mathrm{CFU} / \mathrm{mL}$ at $-70^{\circ} \mathrm{C}$. Minimal inhibitory concentration and minimal bactericidal concentration for ceftriaxone determined by broth microdilution were 0.0625 and $0.125 \mathrm{mg} / \mathrm{L}$, respectively.

Animal model. Animal experiments were performed in accordance with national animal experimentation guidelines and were approved by the District Government of Braunschweig, Lower Saxony. Anesthetized rabbits were infected by intracisternal injection of $300 \mu \mathrm{L}$ saline (23) containing $\log _{10} 3.5$ CFU (median, $\log _{10} 3.4-4.8 \mathrm{CFU}$ ) E. coli. Cisternal CSF and arterial blood were drawn at $0,12,14,18$, and $24 \mathrm{~h}$. At each time point, CSF leukocytes were counted and bacterial titers were determined. The remaining CSF as well as the arterial blood anticoagulated with EDTA were immediately centrifuged at $3000 \times g$ for $10 \mathrm{~min}$, and the supernatants were frozen in liquid nitrogen and stored at $-70^{\circ} \mathrm{C}$. At $23.5 \mathrm{~h}$ post infection, an arterial blood gas analysis was performed (Radiometer ABL 605, Diamond Diagnostics, Holliston, MA) to determine arterial oxygen $\left(\mathrm{Po}_{2}\right)$ and carbon dioxide tension $\left(\mathrm{PCO}_{2}\right)$ and $\mathrm{pH}$. The animals were killed at $24 \mathrm{~h}$ post infection (23).

Treatment. Before infection, animals were randomized for treatment with dexamethasone or an equal volume of saline. Twelve hours post infection, all animals $(n=34)$ received intravenous antibiotic treatment (ceftriaxone, $125 \mathrm{mg} / \mathrm{kg}$ body weight, Hoffmann-La Roche, Grenzach-Wyhlen, Germany). In 17 animals, dexamethasone was administered as bolus injection intravenously ( $1 \mathrm{mg} / \mathrm{mL}$ dexamethasone in saline) $15 \mathrm{~min}$ before onset of antibiotic treatment and $6 \mathrm{~h}$ later. In a second trial, uninfected controls $(n=8)$ undergoing the same procedure including anesthesia, intracisternal injection of $300 \mu \mathrm{L}$ saline, ceftriaxone treatment, and repeated withdrawal of CSF and blood, were randomized for treatment with dexamethasone or saline. Dexamethasone (Ratiopharm, Ulm, Germany) was administered in a dose of $1 \mathrm{mg} / \mathrm{kg}$ body weight to compensate different clearance rates between rabbits and infants (usual dose in children: $0.15 \mathrm{mg} / \mathrm{kg}$ body weight). In humans, pharmacokinetic data are available for doses of $0.10-0.37 \mathrm{mg} / \mathrm{kg}$ body weight [clearance of healthy adult men: $0.189 \mathrm{~L} / \mathrm{h} / \mathrm{kg}(24)$; clearance in neonates: $0.143 \mathrm{~L} / \mathrm{h} / \mathrm{kg}(25)]$. In rabbits, the dexamethasone clearance was determined after intravenous application of 2 or $10 \mathrm{mg} / \mathrm{kg}$ body weight: The clearance decreased with higher doses, suggesting nonlinear pharmacokinetics (26). Thus, the clearance of dexamethasone after application of $1 \mathrm{mg} / \mathrm{kg}$ in rabbits is probably substantially higher than the dexamethasone clearance after application of $2 \mathrm{mg} / \mathrm{kg}(0.312 \mathrm{~L} / \mathrm{h} / \mathrm{kg})(26)$ and therefore a multiple of the clearance in infants and children. Accordingly, most studies with rabbits used dexamethasone doses of $1 \mathrm{mg} / \mathrm{kg}$ or more for a variety of disease models, including meningitis (27-29).
Analysis of CSF . Protein content was quantified using the BCA Protein Assay (Pierce, Rockford, IL), with BSA as standard according to the manufacturer's instruction. CSF lactate was determined enzymatically (Rolf Greiner Biochemica, Flacht, Germany). The global neuronal destruction marker NSE was quantified in CSF by ELISA with mouse anti-human MAb against the $\gamma$-subunit of NSE (DRG Instruments, Marburg, Germany). PGE2 in CSF was quantified using a commercially available enzyme immunoassay (R \& D Systems, Minneapolis, MN). Tumor necrosis factor- $\alpha$ (TNF- $\alpha$ ) was measured in CSF by ELISA. A polyclonal sheep anti-rabbit TNF- $\alpha$ antibody was used as coating antibody, a polyclonal biotin-labeled sheep anti-rabbit TNF- $\alpha$ antibody was used as detection antibody [both in-house preparations of the National Institute for Biologic Standards and Control (NIBSC), Potters Bar, Hertfordshire, England] and TNF- $\alpha$-containing conditioned medium (BD PharMingen, San Diego, CA) was used as standard. CSF bacterial titers were quantified by plating serial 10 -fold dilutions on blood agar plates, which were subsequently incubated for $20 \mathrm{~h}$ at $37^{\circ} \mathrm{C}(30)$. Ceftriaxone concentration in plasma and CSF was determined by the agar well diffusion technique in Mueller-Hinton agar with E. coli (ATCC 25922), as described previously (30).

Histopathology. Immediately after sacrifice, the animals' brains were removed and fixed in $4 \%$ paraformaldehyde and embedded in paraffin. In situ tailing and HE staining were performed as described previously (23).

Quantification of apoptotic neurons. Four coronal sections from each rabbit's left hemisphere were histologically analyzed using the Analysis Software Imaging System (BX51, Olympus, Hamburg, Germany; software AnalySIS 3.2, Soft Imaging System GmbH, Münster, Germany). In coded sections, a blinded observer quantified apoptotic cells with typical morphology after in situ labeling of DNA strand breaks. The number of apoptotic neurons was related to the area of the granule cell layer of the hippocampal dentate gyrus, measured in an adjacent HE-stained section.

Estimation of ischemic neuronal damage. An estimate was made of the extent of ischemic damage by histologic evaluation of 4 HE-stained coronal sections of the hippocampal region per animal. The ischemic areas were morphologically identified and expressed as percentage of the areas of the whole section.

Statistical analysis. In the presence of normal Gaussian distribution, parameters of two groups were compared using an unpaired $t$ test. In the absence of normal distribution statistical analysis was performed using the two-tailed Mann-Whitney $U$ test. To compare apoptosis rates between all four animal groups (uninfected controls, uninfected dexamethasone-treated rabbits, infected controls, and infected dexamethasone-treated animals), twotailed ANOVA with the Tukey-Kramer multiple comparisons test was performed. A $p$ value $<0.05$ was considered significant.

\section{RESULTS}

Characteristics of disease. The course of disease in this rabbit model of $E$. coli meningitis was faster than the progression previously observed in pneumococcal meningitis. Two of 17 and 3 of 17 rabbits in the dexamethasone-treated group and the control group, respectively, died before the end of the experiment. Only animals surviving $24 \mathrm{~h}$ post infection were included in the analysis to avoid effects of survival time on neuronal apoptosis or infarction rate. Animals dying prematurely did not differ substantially from the surviving animals in body temperature, CSF pleocytosis, and bacterial load. Twelve hours after intracisternal inoculation of $E$. coli, rabbits developed full clinical presentation of meningitis [bacterial CSF load $\log _{10} 7.78$ (5.00-9.60) (median, min, max)] and septicemia [bacteriemia of $\log _{10} 3.00 \mathrm{CFU} / \mathrm{mL}\left(\log _{10}<2.0\right.$, 5.30 (median, min, max)] without relevant differences between the two treatment groups. Systemic inflammation parameters in E. coli meningitis including body temperature, arterial $\mathrm{PO}_{2}, \mathrm{PCO}_{2}$ and $\mathrm{pH}$ at $23.5 \mathrm{~h}$ post infection did not differ significantly between the dexamethasone-treated and the control group (Table 1).

CSF analysis. Maximal CSF concentrations of PGE2 were reached at $14 \mathrm{~h}$ post infection in both groups. The antiinflammatory activity of dexamethasone resulted in a significant reduction of CSF PGE2 concentrations in the dexametha- 
Table 1. Parameters of CSF inflammation, neuronal damage and systemic inflammation in uninfected rabbits and rabbits with E. coli meningitis

\begin{tabular}{|c|c|c|c|c|}
\hline \multirow[b]{2}{*}{ Time after infection } & \multicolumn{2}{|c|}{ Uninfected controls $(n=4)$} & \multicolumn{2}{|c|}{ Uninfected DXM $*(n=4)$} \\
\hline & $12 \mathrm{~h}$ & $24 \mathrm{~h}$ & $12 \mathrm{~h}$ & $24 \mathrm{~h}$ \\
\hline Leukocytes $($ cells $/ \mu \mathrm{L}) \dagger$ & $6.5(5 ; 31)$ & $3.5(0.5 ; 15.5)$ & $19(13.5 ; 38)$ & $7.5(6 ; 9.5)$ \\
\hline Protein $(\mathrm{mg} / \mathrm{L}) \S$ & $755 \pm 220$ & $1213 \pm 600$ & $789 \pm 63$ & $1267 \pm 271$ \\
\hline \multicolumn{5}{|l|}{$\operatorname{NSE}(\mu \mathrm{g} / \mathrm{L}) \dagger$} \\
\hline \multirow{4}{*}{$\begin{array}{l}\text { Body temperature }\left({ }^{\circ} \mathrm{C}\right) \S \\
\mathrm{Po}_{2} \S \\
\mathrm{PCO}_{2} \S \\
\mathrm{pH} \S\end{array}$} & $37.6 \pm 0.4$ & $37.6 \pm 0.3$ & $37.9 \pm 0.3$ & $37.7 \pm 0.4$ \\
\hline & & & & \\
\hline & & & & \\
\hline & \multicolumn{2}{|c|}{ Infected controls $(n=14-15)$} & \multicolumn{2}{|c|}{ Infected DXM $*(n=12-14)$} \\
\hline Time after infection & $12 \mathrm{~h}$ & $24 \mathrm{~h}$ & $12 \mathrm{~h}$ & $24 \mathrm{~h}$ \\
\hline Leukocytes $($ cells $/ \mu \mathrm{L}) \dagger$ & $674.5(387.5 ; 1765.5)$ & $9942(3616 ; 14592)$ & $816(338 ; 1312)$ & $4949(3307 ; 11328)$ \\
\hline Protein $(\mathrm{mg} / \mathrm{L}) \S$ & $3546 \pm 3311$ & $5808 \pm 1925$ & $2919 \pm 761$ & $5114 \pm 2074$ \\
\hline Lactate $(\mathrm{mmol} / \mathrm{L}) \S$ & $8.5 \pm 4.4$ & $14.3 \pm 5.4$ & $8.5 \pm 3.1$ & $11.8 \pm 4.0$ \\
\hline $\mathrm{pH} \S$ & & $7.56 \pm 0.11$ & & $7.50 \pm 0.10$ \\
\hline
\end{tabular}

* DXM = group with adjunctive dexamethasone treatment.

$\dagger$ Median (25th; 75th percentile), no significant difference between dexamethasone-treated and respective control group, p $>0.05$ ( $U$ test).

$\S$ Mean $\pm \mathrm{SD}$, no significant difference between dexamethasone-treated and respective control group, $p>0.05$ ( $t$ test).

sone-treated group at $18 \mathrm{~h}(p=0.02, t$ test, Fig. $1 A)$. The TNF- $\alpha$ maximum CSF concentration was also reached at $14 \mathrm{~h}$ post infection, with a remarkable but not significant reduction by adjunctive dexamethasone treatment $(p=0.40, U$ test, Fig. 1B). A weak effect of dexamethasone treatment on CSF protein and lactate concentrations was noted when the mean values at 12 and $24 \mathrm{~h}$ between the treatment groups were compared, but this difference also failed to reach statistical significance (Table 1). The CSF leukocyte densities did not differ. Dexamethasone did not affect ceftriaxone CSF concentration $24 \mathrm{~h}$ post infection $[13.1 \pm 6.0$ versus $13.8 \pm 8.4$ $\mu \mathrm{g} / \mathrm{mL}$ in controls (means $\pm \mathrm{SD}$ ), $p=0.80, t$ test] or bacterial elimination [bacterial CSF load $24 \mathrm{~h}$ post infection: $\log _{10} 1.74$
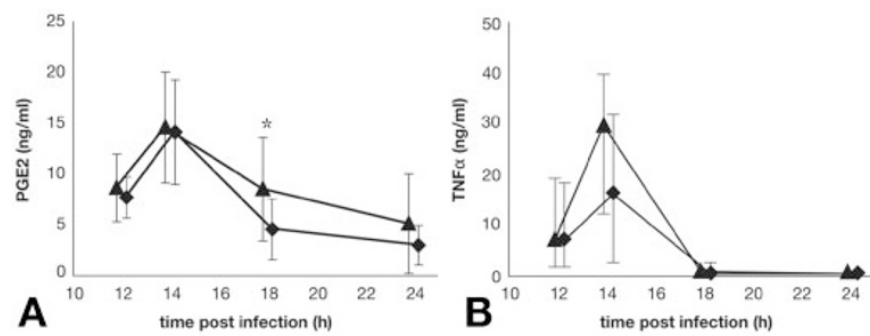

Figure 1. CSF concentrations of PGE2 and TNF- $\alpha$ in experimental ceftriaxone-treated $E$. coli meningitis with and without adjunctive dexamethasone treatment. PGE2 concentration data $(A)$ showed normal Gaussian distribution and were analyzed using $t$ test (mean $\pm \mathrm{SD}$ ). Because TNF- $\alpha$ concentration data were not normally distributed $(B)$, statistical analysis was performed using the Mann-Whitney $U$ test (median, 25th and 75th percentile). Mean (PGE2) or median (TNF- $\alpha$ ) values of rabbits treated with ceftriaxone alone are represented by black triangles $(n=12-14)$ and of the group treated with adjunctive dexamethasone by black diamonds $(n=14-15)$. Dexamethasonetreated animals showed reduced prostaglandin and cytokine levels, but only the reduction of PGE2 at $18 \mathrm{~h}$ post infection reached statistical significance $(* p=0.02)$. $\left(\log _{10}<2.0,4.00\right)$ versus $\log _{10} 2.54\left(\log _{10}<2.0,3.30\right.$ (median, min, max), $p=0.55, U$ test].

Global neuronal damage. NSE in CSF as an indicator of neuronal destruction was quantified at $12 \mathrm{~h}$ and $23.5 \mathrm{~h}$ after infection (Table 1). Comparable to normal human CSF [5$20 \mathrm{ng} / \mathrm{mL}$, (31)], NSE in uninfected rabbit CSF ranged from 8 to $15 \mathrm{ng} / \mathrm{mL}(n=5)$. During E. coli meningitis, we observed higher concentrations of NSE than in pneumococcal meningitis (11). Histologically, cerebral infarctions were present in a higher percentage than in pneumococcal meningitis, ranging from no detectable infarction area in most animals to large infarction areas in a few rabbits (ischemic area: maximum $37 \%$, median 0\%). The NSE concentration in the CSF moderately correlated with the rate of neuronal apoptosis (Spearman's rank correlation coefficient $r_{S}=0.46, p=0.03$ ), whereas no correlation was found between NSE concentration and cerebral infarction rate because of the high number of animals without detectable infarctions. Neither the NSE concentration at $23.5 \mathrm{~h}$ post infection, nor the percentage of cerebral infarction $24 \mathrm{~h}$ after infection differed significantly between dexamethasone-treated and control animals (Table 1, $p=0.80$ and 0.33 , respectively, both $U$ test).

Neuronal apoptosis in the hippocampal dentate gyrus. Neuronal apoptosis was regularly observed in this rabbit model of $E$. coli meningitis in the granule cell layer of the dentate gyrus at $24 \mathrm{~h}$ after infection. Apoptotic cells were identified by in situ labeling of DNA strand breaks and confirmed by morphologic criteria. In experimental E. coli meningitis the rate of apoptotic neurons ranged from 38.6 to 570 per $\mathrm{mm}^{2}$ (area of the granule cell layer). To ensure that the observed neuronal apoptosis was caused by meningitis, control animals without bacterial infection were investigated. Previously healthy rabbits that were killed immediately with- 


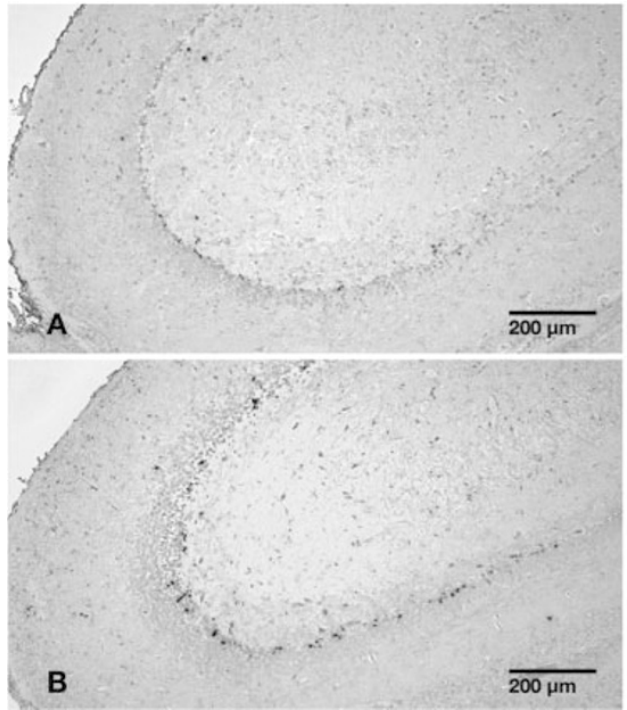

Figure 2. Neuronal apoptosis of granule cells of the hippocampal dentate gyrus visualized by in situ tailing. In uninfected rabbits, no significant difference was found in the rate of apoptotic neurons between dexamethasone-treated animals (DXM) and controls $(\mathrm{C})$, whereas under conditions of experimental E. coli meningitis, adjunctive treatment with dexamethasone $(B)$ resulted in a significant increase in the density of apoptotic granule cells in comparison to infected controls $(A, C)\left({ }^{*} p<0.01\right.$, ANOVA with post test). In $(C)$, symbols represent single measurements of each individual animals (uninfected controls: empty triangles; uninfected dexamethasone-treated animals: empty diamonds; infected controls: black triangles; infected dexamethasone-treated animals: black diamonds), and horizontal bars represent means. out long-term anesthesia exhibited approximately 10 apoptotic neuronal cells $/ \mathrm{mm}^{2}$ in the hippocampal dentate gyrus (11). In uninfected rabbits subjected to the experimental procedure applied in this project, including long-term anesthesia, antibiotic treatment with ceftriaxone, and repeated suboccipital punctures, approximately 40 apoptotic neurons $/ \mathrm{mm}^{2}$ were detected. Adjunctive dexamethasone treatment of these uninfected rabbits revealed a slight nonsignificant increase of the mean rate of neuronal apoptosis $(49.6 \pm 31.5$ versus $41.2 \pm$ 14.7 , mean $\pm \mathrm{SD}, p=0.65, t$ test) as a consequence of the relatively high apoptosis rate in one animal (Fig. 2). This rabbit suffered from artificial subarachnoid hemorrhage caused by accidental bloody suboccipital puncture, exceptionally occurring during this model. In rabbits with E. coli meningitis the rate of neuronal apoptosis was substantially higher than in uninfected rabbits. In dexamethasone-treated rabbits with $E$. coli meningitis the rate of neuronal apoptosis was significantly increased in comparison to infected control animals $(p<0.01$, ANOVA with Tukey-Kramer multiple comparison test, Fig. 2).

\section{DISCUSSION}

In the present study, dexamethasone as adjunctive therapy for Gram-negative E. coli-meningitis resulted in an increased rate of apoptotic neuronal cell death in the hippocampal dentate gyrus of experimental rabbits. This finding confirms and expands previous observations in animal models of pneumococcal meningitis, where dexamethasone also led to an increased hippocampal neuronal apoptosis rate $(11,12)$. Thus, the induction of hippocampal apoptotic neuronal cell death by dexamethasone occurs both in Gram-positive and Gramnegative meningitis.

Neurons in the hippocampal formation possess a high density of glucocorticoid and mineralocorticoid receptors (32). A complex interaction exists between systemic corticoid levels and cell viability of hippocampal neurons: activation of mineralocorticoid receptors prevents granule cell apoptosis and stimulation of glucocorticoid receptors facilitates it (33). Be- cause in uninfected rabbits only a weak increase in the mean rate of neuronal apoptosis was found after dexamethasone treatment, we conclude that in healthy animals the proapoptotic effect of the dexamethasone dose chosen was minimal. The proapoptotic effect of dexamethasone in Gram-positive and Gram-negative meningitis is probably a result of several effects, including inhibition of glutamate reuptake and free radicals resulting in an increased susceptibility of dentate granule cells to adjunctive glucocorticoid treatment (34).

Hippocampal neuronal cell death is considered one morphologic correlate of the frequent neuropsychological deficits in survivors of bacterial meningitis. A detrimental effect of glucocorticoid application on neuropsychological function in patients has been described in human newborns treated for lung disease of prematurity (35) or adult patients treated for chronic systemic diseases (36). The suspicion that dexamethasone may aggravate neuropsychological deficits in patients with meningitis as a consequence of hippocampal neuronal cell death is supported by experimental data in the infant rat pneumococcal meningitis model, where dexamethasone reduced the animals' learning capacity (12). No detrimental effect of dexamethasone application was found on the global neuronal damage marker NSE or with regard to the frequency and severity of cerebral ischemic damage.

Comparable to a beneficial effect of low-dose glucocorticoid administration in sepsis (7), the European Dexamethasone Study showed a reduced morbidity and mortality of adjunctive dexamethasone treatment (6), attributable to a reduction of systemic complications (8). In infants and children, a dexamethasone-induced decrease of mediators of inflammation in the CSF including PGE2 has been described (4). Similarly, in the rabbit model of Streptococcus pneumoniae meningitis, dexamethasone modulated the secondary inflammatory response induced by the onset of bacteriolytic antibiotic treatment in animals with high initial bacterial concentrations ( $\geq 5.6 \log _{10} \mathrm{CFU} / \mathrm{mL}$ ) (27). According to these data, especially patients with high bacterial load should benefit from antiinflammatory dexamethasone treatment or other 
strategies to reduce the secondary inflammatory response. In this study, PGE2 and TNF- $\alpha$ were monitored as early components of the inflammatory cascade. The prostanoid PGE2 increases blood flow, vascular permeability, and edema. It mediates fever generation and interacts with various pathways of the innate immune system in a concentration-dependent manner (37). In our model of E. coli meningitis, PGE2 and TNF- $\alpha$ peak concentrations were reached $2 \mathrm{~h}$ after onset of ceftriaxone treatment, reflecting the liberation of proinflammatory compounds such as endotoxin by bacterial lysis. Adjunctive dexamethasone treatment did not attenuate antibioticinduced PGE2 peak concentration but decreased PGE2 concentrations during the course of the disease (Fig. 1A). $\mathrm{TNF}-\alpha$ is a key trigger of the inflammatory response to Gram-negative bacteria, influencing vascular permeability, expression of adhesion molecules, establishment of a leukocyte-rich inflammatory infiltrate and production of other cytokines (38). In our model, TNF- $\alpha$ concentrations in CSF reached and exceeded TNF- $\alpha$ levels observed in patients with disturbed consciousness [about $3000 \mathrm{pg} / \mathrm{mL}$ (39)] (Fig. 1B). Adjunctive dexamethasone treatment decreased TNF- $\alpha$ concentrations in CSF, but this effect did not reach statistical significance. CSF leukocytes count, CSF protein, and CSF lactate are parameters of inflammation with diagnostic and prognostic relevance for bacterial meningitis. Only a slight effect of dexamethasone on these parameters resulting in a nonsignificant reduction of protein and lactate was noted. Dexamethasone had no significant effect on systemic sepsisassociated parameters such as arterial oxygen saturation and $\mathrm{pH}$ or on ceftriaxone concentrations in CSF and bacterial elimination.

In conclusion, the present study demonstrates an increased rate of neuronal apoptosis in the hippocampal dentate gyrus caused by adjunctive therapy with dexamethasone for $E$. coli meningitis, expanding previous data restricted to pneumococcal meningitis.

In developed countries the actual standard therapy of community-acquired meningitis in children and adults includes the adjunctive administration of dexamethasone additive to antibiotic treatment. In view of the proapoptotic effect of adjunctive dexamethasone on hippocampal neuronal cells in animal models of Gram-positive and Gram-negative meningitis, dexamethasone may not be the ideal adjunct. It should be used with caution in forms of bacterial meningitis for which no evidence-based data supporting benefit are available, such as neonatal meningitis, bacillary Gram-negative meningitis, or nosocomial forms of meningitis (e.g. following neurosurgery). Further investigations should focus on the evaluation of alternative treatment strategies, including neuroprotective agents.

\section{REFERENCES}

1. Nau R, Bruck W 2002 Neuronal injury in bacterial meningitis: mechanisms and implications for therapy. Trends Neurosci 25:38-45

2. Nau R, Eiffert H 2005 Minimizing the release of proinflammatory and toxic bacterial products within the host: a promising approach to improve outcome in lifethreatening infections. FEMS Immunol Med Microbiol 44:1-16

3. Kadurugamuwa JL, Modi K, Coquoz O, Rice B, Smith S, Contag PR, Purchio T 2005 Reduction of astrogliosis by early treatment of pneumococcal meningitis measured by simultaneous imaging, in vivo, of the pathogen and host response. Infect Immun 73:7836-7843

4. Mustafa MM, Ramilo O, Saez-Llorens X, Olsen KD, Magness RR, McCracken GHJr 1990 Cerebrospinal fluid prostaglandins, interleukin 1 beta, and tumor necrosis factor in bacterial meningitis. Clinical and laboratory correlations in placebo-treated and dexamethasone-treated patients. Am J Dis Child 144:883-887

5. Mukai AO, Krebs VL, Bertoli CJ, Okay TS 2006 TNF-alpha and IL-6 in the diagnosis of bacterial and aseptic meningitis in children. Pediatr Neurol 34:25-29

6. de Gans J, van de Beek D 2002 Dexamethasone in adults with bacterial meningitis. N Engl J Med 347:1549-1556

7. Annane D, Bellissant E, Bollaert PE, Briegel J, Keh D, Kupfer Y 2004 Corticosteroids for severe sepsis and septic shock: a systematic review and meta-analysis. BMJ 329:480

8. van de Beek D, de Gans J 2004 Dexamethasone and pneumococcal meningitis. Ann Intern Med 141:327

9. Molyneux EM, Walsh AL, Forsyth H, Tembo M, Mwenechanya J, Kayira K, Bwanaisa L, Njobvu A, Rogerson S, Malenga G 2002 Dexamethasone treatment in childhood bacterial meningitis in Malawi: a randomised controlled trial. Lancet 360:211-218

10. Qazi SA, Khan MA, Mughal N, Ahmad M, Joomro B, Sakata Y, Kuriya N, Matsuishi T, Abbas KA, Yamashita F 1996 Dexamethasone and bacterial meningitis in Pakistan. Arch Dis Child 75:482-488

11. Zysk G, Bruck W, Gerber J, Bruck Y, Prange HW, Nau R 1996 Anti-inflammatory treatment influences neuronal apoptotic cell death in the dentate gyrus in experimental pneumococcal meningitis. J Neuropathol Exp Neurol 55:722-728

12. Leib SL, Heimgartner C, Bifrare YD, Loeffler JM, Tauber MG 2003 Dexamethasone aggravates hippocampal apoptosis and learning deficiency in pneumococcal meningitis in infant rats. Pediatr Res 54:353-357

13. Nau R, Soto A, Bruck W 1999 Apoptosis of neurons in the dentate gyrus in humans suffering from bacterial meningitis. J Neuropathol Exp Neurol 58:265-274

14. Free SL, Li LM, Fish DR, Shorvon SD, Stevens JM 1996 Bilateral hippocampal volume loss in patients with a history of encephalitis or meningitis. Epilepsia 37:400-405

15. Odio CM, Faingezicht I, Paris M, Nassar M, Baltodano A, Rogers J, Saez-Llorens X, Olsen KD, McCracken GHJr 1991 The beneficial effects of early dexamethasone administration in infants and children with bacterial meningitis. N Engl J Med 324:1525-1531.

16. Schaad UB, Lips U, Gnehm HE, Blumberg A, Heinzer I, Wedgwood J 1993 Dexamethasone therapy for bacterial meningitis in children. Swiss Meningitis Study Group. Lancet 342:457-461

17. Chaudhuri A 2004 Adjunctive dexamethasone treatment in acute bacterial meningitis. Lancet Neurol 3:54-62

18. Gupta S, Tuladhar AB 2004 Does early administration of dexamethasone improve neurological outcome in children with meningococcal meningitis? Arch Dis Child 89:82-83

19. Unhanand M, Mustafa MM, McCracken GHJr., Nelson JD 1993 Gram-negative enteric bacillary meningitis: a twenty-one-year experience. J Pediatr 122:15-21

20. Kim KS 2003 Pathogenesis of bacterial meningitis: from bacteriaemia to neuronal injury. Nat Rev Neurosci 4:376-385

21. Mofredj A, Guerin JM, Leibinger F, Mamoudi R 2000 Spontaneous Escherichia coli meningitis in an adult. Scand J Infect Dis 32:699-700

22. Chotmongkol V, Techoruangwiwat C 2000 Community acquired-bacterial meningitis in adults. Southeast Asian J Trop Med Public Health 31:506-508

23. Gerber J, Pohl K, Sander V, Bunkowski S, Nau R 2003 Rifampin followed by ceftriaxone for experimental meningitis decreases lipoteichoic acid concentrations in cerebrospinal fluid and reduces neuronal damage in comparison to ceftriaxone alone. Antimicrob Agents Chemother 47:1313-1317

24. Tsuei SE, Moore RG, Ashley JJ, McBride WG 1979 Disposition of synthetic glucocorticoids. I. Pharmacokinetics of dexamethasone in healthy adults. J Pharmacokinet Biopharm 7:249-264

25. Charles B, Schild P, Steer P, Cartwright D, Donovan T 1993 Pharmacokinetics of dexamethasone following single-dose intravenous administration to extremely low birth weight infants. Dev Pharmacol Ther 20:205-210

26. Trenque T, Lamiable D, Vistelle R, Millart H, Leperre A, Choisy H 1994 Comparative pharmacokinetics of two diastereoisomers dexamethasone and betamethasone in plasma and cerebrospinal fluid in rabbits. Fundam Clin Pharmacol 8:430-436

27. Lutsar I, Friedland IR, Jafri HS, Wubbel L, Ahmed A, Trujillo M, McCoig CC, McCracken GH Jr 2003 Factors influencing the anti-inflammatory effect of dexamethasone therapy in experimental pneumococcal meningitis. J Antimicrob Chemother 52:651-655.

28. Huang WT, Lin MT, Won SJ 1997 Staphylococcal enterotoxin A-induced fever is associated with increased circulating levels of cytokines in rabbits. Infect Immun 65:2656-2662

29. Kil HK, Alberts MK, Liggitt HD, Bishop MJ 1997 Dexamethasone treatment does not ameliorate subglottic ischemic injury in rabbits. Chest 111:1356-1360

30. Nau R, Zysk G, Schmidt H, Fischer FR, Stringaris AK, Stuertz K, Bruck W 1997 Trovafloxacin delays the antibiotic-induced inflammatory response in experimental pneumococcal meningitis. J Antimicrob Chemother 39:781-788

31. Jacobi C, Reiber H 1988 Clinical relevance of increased neuron-specific enolase concentration in cerebrospinal fluid. Clin Chim Acta 177:49-54

32. Reul JM, de Kloet ER 1985 Two receptor systems for corticosterone in rat brain: microdistribution and differential occupation. Endocrinology 117:2505-2511

33. Almeida OF, Conde GL, Crochemore C, Demeneix BA, Fischer D, Hassan AH, Meyer M, Holsboer F, Michaelidis TM 2000 Subtle shifts in the ratio between pro-- 
and antiapoptotic molecules after activation of corticosteroid receptors decide neuronal fate. FASEB J 14:779-790

34. Tumani H, Smirnov A, Barchfeld S, Olgemoller U, Maier K, Lange P, Bruck W, Nau R 2000 Inhibition of glutamine synthetase in rabbit pneumococcal meningitis is associated with neuronal apoptosis in the dentate gyrus. Glia 30:11-18

35. Yeh TF, Lin YJ, Lin HC, Huang CC, Hsieh WS, Lin CH, Tsai CH 2004 Outcomes at school age after postnatal dexamethasone therapy for lung disease of prematurity. N Engl J Med 350:1304-1313

36. Keenan PA, Jacobson MW, Soleymani RM, Mayes MD, Stress ME, Yaldoo DT
1996 The effect on memory of chronic prednisone treatment in patients with systemic disease. Neurology 47:1396-1402

37. Yoshikai Y 2001 Roles of prostaglandins and leukotrienes in acute inflammation caused by bacterial infection. Curr Opin Infect Dis 14:257-263

38. Benveniste EN 1992 Inflammatory cytokines within the central nervous system: sources, function, and mechanism of action. Am J Physiol 263:C1-C16

39. Ohga S, Okada K, Ueda K, Takada H, Ohta M, Aoki T, Kinukawa N, Miyazaki S, Hara T 1999 Cerebrospinal fluid cytokine levels and dexamethasone therapy in bacterial meningitis. J Infect 39:55-60 